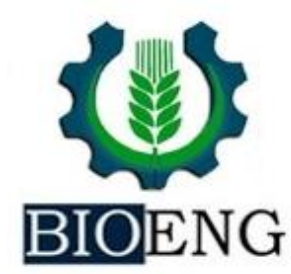

\title{
USO NÃO AGRÍCOLA DO SOLO: A TINTA DE TERRA COMO INOVAÇÃO TECNOLÓGICA E SUSTENTÁVEL
}

${ }^{1}$ UFCG - Universidade Federal de Campina Grande, Campus de Sumé, PB, Brasil

${ }^{2}$ UFVJM - Universidade Federal dos Vales do Jequitinhonha e Mucuri, Campus de Diamantina, MG, Brasil

${ }^{3}$ UFRN - Universidade Federal do Rio Grande do Norte, Campus de Natal, RN, Brasil

Article history: Received 16 March 2018; Received in revised form 21 April 2018; Accepted 26 April 2018; Available online 28 June 2018.

\section{RESUMO}

A exploração indiscriminada dos recursos naturais direciona o mercado a buscar novas tecnologias como alerta à possível escassez de materiais. No contexto da construção a utilização de novas alternativas para pintura é uma urgência e o uso da tinta a base de terra é uma alternativa inovadora, econômica e viável, considerando o apelo socioambiental da proposta. O trabalho objetiva apresentar a percepção de agricultores sobre a pintura com tinta de terra, como ecotecnologia social para a valorização das potencialidades não agrícolas do solo e oportunidade de geração de trabalho e renda. As atividades aconteceram numa associação rural do Cariri paraibano. Inicialmente foi aplicado um questionário semiestruturado para verificar o entendimento dos participantes sobre a morfologia e uso não agrícola do solo. A seguir realizou-se a oficina de pintura com terra (geotinta). Os resultados apresentam a ausência de conceitos sobre as características do solo e suas potencialidades não agrícolas. Após a oficina a percepção dos agricultores mudou e estes revelaram-se entusiasmados pela tinta de terra, como inovação para pintura da casas e como oportunidade de agregar renda pelo artesanato. Evidencia-se a geotinta como possibilidade para disseminação de conceitos sobre o solo, promoção de posturas sustentáveis e ecotecnologia para inovação.

Palavras-chave: Solo. Tinta de terra. Ecotecnologia. Geotinta.

\section{NON AGRICULTURAL USE OF SOIL: EARTH INK AS TECHNOLOGICAL AND SUSTAINABLE INNOVATION}

\begin{abstract}
The indiscriminate exploitation of natural resources directs the market to seek new technologies as a warning to the possible shortage of materials. In the context of construction, the use of new paint alternatives is an urgency and the use of earth-based paint is an innovative, economical and viable alternative, considering the socio-environmental appeal of the proposal. The objective of this work is to present the perception of farmers about the paint with earthen paint, such as social ecotechnology for the valorization of the non - agricultural potentials of the soil and the opportunity to generate work and income. The activities took place in a rural association in Cariri (PB). Initially a semi-structured questionnaire was applied to verify the participants' understanding of the morphology and non-agricultural use of the soil. Then the painting workshop with earth (geotinta) was realized. The results show
\end{abstract}

\footnotetext{
vital.adriana@gmail.com
} 
the absence of concepts about soil characteristics and their non - agricultural potential. After the workshop the perception of the farmers changed and these were enthusiastic about the paint of earth, as innovation for painting of the houses and as opportunity to add income by the craftsmanship. Geotint is evidenced as a possibility for dissemination of concepts on the soil, promotion of sustainable postures and ecotechnology for innovation.

Keywords: Soil. Earthenware. Ecotechnology. Geotinta.

\section{INTRODUÇÃO}

O solo é o recurso natural fundamental à manutenção da vida. Embora pouco conhecido e valorizado, a relação do homem com o solo remonta aos primórdios da história da humanidade: além do uso agrícola, estudos relatam também o uso não agrícola dos solos e materiais minerais no tratamento de enfermidades humanas (ALVES; MARQUES, 2005; LIMA et al, 2009), na alimentação humana (BROWMAN; GUNDERSEN, 1993), na pintura corporal dos diversos rituais dos indígenas e aborígenes (OLLIER et al, 1971) e nas pinturas rupestres, evidenciando relatos da história humana, assim a pintura com terra situa-se como das mais antigas artes.

As práticas de pintura que usam o solo como pigmentos naturais existem desde os primórdios da humanidade e seguem até os dias de hoje, sendo largamente utilizadas nos mais variados locais e, sobretudo no ambiente rural, mas é grande atrativo no mundo moderno das cidades grandes (CARVALHO, 2007).

Esse processo de baixo custo e impacto ambiental mínimo, compreende produtos, técnicas e metodologias que visam a transformação social, favorecendo a organização das comunidades, desenvolvendo a criatividade e ocasionando a melhoria da autoestima dos envolvidos, além de proporcionar alternativa de renda (VITAL et al., 2011).

$\mathrm{O}$ uso da tinta de terra pode ser igualmente uma alternativa de valorização das potencialidades do solo, geração de trabalho, renda, bem como fator de cidadania, apresentando-se como uma proposta inovadora de valorização do solo (CAPECHE, 2010; SILVA et al., 2013).
A cor é considerada uma das características morfológicas mais importantes, pois permite fazer deduções lógicas sobre os atributos físicos, químicos, biológicos e mineralógicos do solo. Os solos podem se apresentar sob variadas cores, indo do claro ao mais escuro, indicando a presença de quartzo, matéria orgânica, ferro. Nesse momento fez-se uso da Carta de Cores de Munsell, que é uma ferramenta utilizada na Agronomia e na Pedologia para identificação da cor de um solo e que consiste em um caderno com uma série de exemplos de cores relacionados cada um a um código de três números: Matiz, Valor e Croma. O primeiro refere-se a relação entre os pigmentos de cor amarela e vermelha. $\mathrm{O}$ valor indica a proporção das cores branca e preta no solo, enquanto o Croma menciona a contribuição do Matiz na coloração (RESENDE et al., 2002). Esses conceitos foram passados brevemente apenas para contextualizar a riqueza e diversidade dos solos.

A sustentabilidade socioambiental está relacionada à implantação de ações sistêmicas, que "promovam real qualidade de vida às atuais e futuras gerações, respeitando as diversidades culturais e potencializando as características regionais" (CASAGRANDE, 2011).

Os princípios de sustentabilidade cada vez mais orientam os diversos segmentos da sociedade, pois o mercado consumidor está focado em produtos que causem menos impactos ao meio ambiente, uma vez que a mídia visibiliza cotidianamente o uso predatório, o manejo inadequado e o não aproveitamento dos resíduos e co-produtos originados da exploração dos recursos ambientais, como 
agentes da degradação e danos ao ambiente a a qualidade de vida das pessoas, e por conseguinte, geradores de escassez e agravantes das mudanças climáticas irreversíveis ocasionadas pelo aumento da temperatura global.

$\mathrm{Na}$ busca pela promoção da sustentabilidade, é imperioso primar pelo uso de materiais alternativos, que causem menos impactos aos recursos ambientais, otimizem processos e minimizem gastos.

Temáticas e princípios direcionados à promoção da sustentabilidade cada vez mais orientam o mercado da construção, considerado um dos setores que mais causa impactos ao meio ambiente, devido ao alto consumo de materiais, energia e geração de resíduos (SANGUINETTO, 2010).

\section{MATERIAL E MÉTODOS}

Realizou-se uma pesquisa de percepção com agricultores, da comunidade rural Salão, município de Serra Branca (PB), por meio da aplicação de questionários sobre as características morfológicas e uso não agrícola do solo. $\mathrm{O}$ estudo de percepção é fundamental, pois permite conhecer a visão de cada um dos indivíduos envolvidos, facilitando a realização de um trabalho com bases locais, partindo da realidade do público alvo, sabendo como os indivíduos percebem o ambiente, suas limitações e potencialidades, podendo ser ainda entendido como uma tomada de

\section{RESULTADOS E DISCUSSÃO}

Quanto ao conhecimento das características do solo, apenas $14 \%$ dos agricultores mencionaram que o solo tem diferenças na cor e na 'aparência', revelando saber empírico sobre duas características morfológicas do solo, fato que permite refletir sobre as ponderações
$\mathrm{Na}$ perspectiva da promoção da sustentabilidade é importante visualizar alternativas que possam agregar valor às práticas camponesas, pela discussão das potencialidades e uso sustentável dos recursos ambientais, assim, o uso do solo para confecção de tinta ecológica (geotinta), ecotecnologia social de elevado apelo ambiental, pode contribuir para valorização e conservação do solo, uma vez que a técnica trabalhada dentro dos princípios da bioarquitetura e bioconstrução, pode contribuir para a inovação e geração de trabalho e renda.

Assim considerando, a pesquisa objetivou verificar a percepção e a aceitabilidade dos agricultores sobre a proposta da pintura da fachada de casas com a tinta a base de terra.

consciência do ambiente pelo ser humano (VILLAR et al, 2008).

Para a realização da oficina, o solo foi coletado em barrancos da estrada da comunidade. As atividades de confecção da tinta de terra foram realizadas com o grupo e constaram de orientações sobre o solo adequado para a tinta, o destorroamento, peneiramento e homogeneização do material. $\mathrm{Na}$ elaboração da tinta de terra, foram usados seis quilos de solo, oito litros de água e dois quilos de cola branca, material suficiente para pintar uma parede de $90 \mathrm{~m}^{2}$.

de Ruellan (1988) ao mencionar que sendo o solo um meio organizado, o homem pode, através do uso e do manejo, transformá-lo e que as alterações podem ser tanto de ordem estrutural como de funcionamento. 


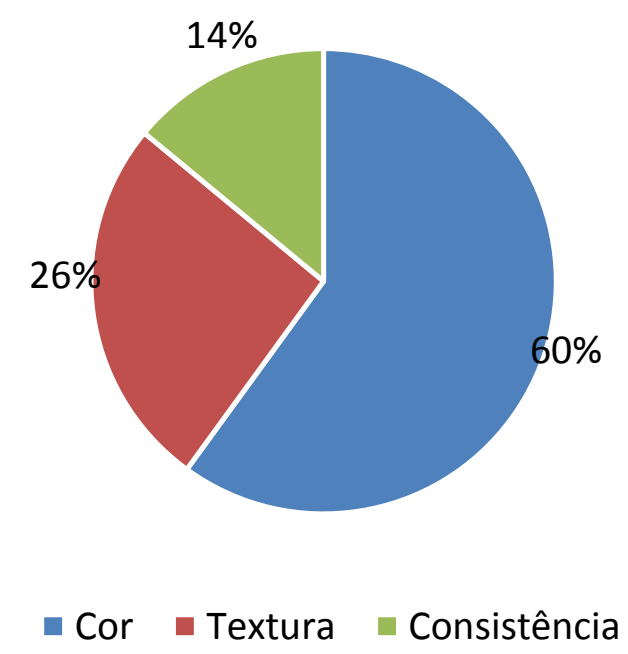

Figura 1. Algumas características morfológicas do solo, segundo os entrevistados.

Segundo LEPSCH (2002), a morfologia do solo pode ser definida como o estudo da aparência do solo em seu ambiente natural, onde a partir dessa aparência é possível notar características que são visíveis a olho nu, ou de fácil percepção quando se observa o solo. $\mathrm{O}$ conjunto de características morfológicas tem papel de extrema importância para identificação do solo, que deverá ser completada com análises de laboratório e assim fazendoum estudo ainda mais detalhado do solo.

Considera-se que uma das soluções para que os problemas de degradação dos solos sejam amenizados é o agricultor ter um conhecimento básico da origem e evolução dos solos na paisagem, já que são eles que lidam no dia a dia com esse recurso da natureza. Para Nóbrega et al (1992), o conhecimento sobre o solo contribui para melhorar a qualidade de vida da população, particularmente porque ajuda a diagnosticar as causas dos problemas ambientais, facilitando consequentemente o diagnóstico dos mesmos.

Questionados sobre as possibilidades de uso não agrícola do solo, apenas 33\% dos agricultores mencionou a confecção de telhas, tijolos e a louça de barro, atividade que ainda faz parte do cotidiano desses sujeitos sociais, desde que na região há uma comunidade de loiceiras.

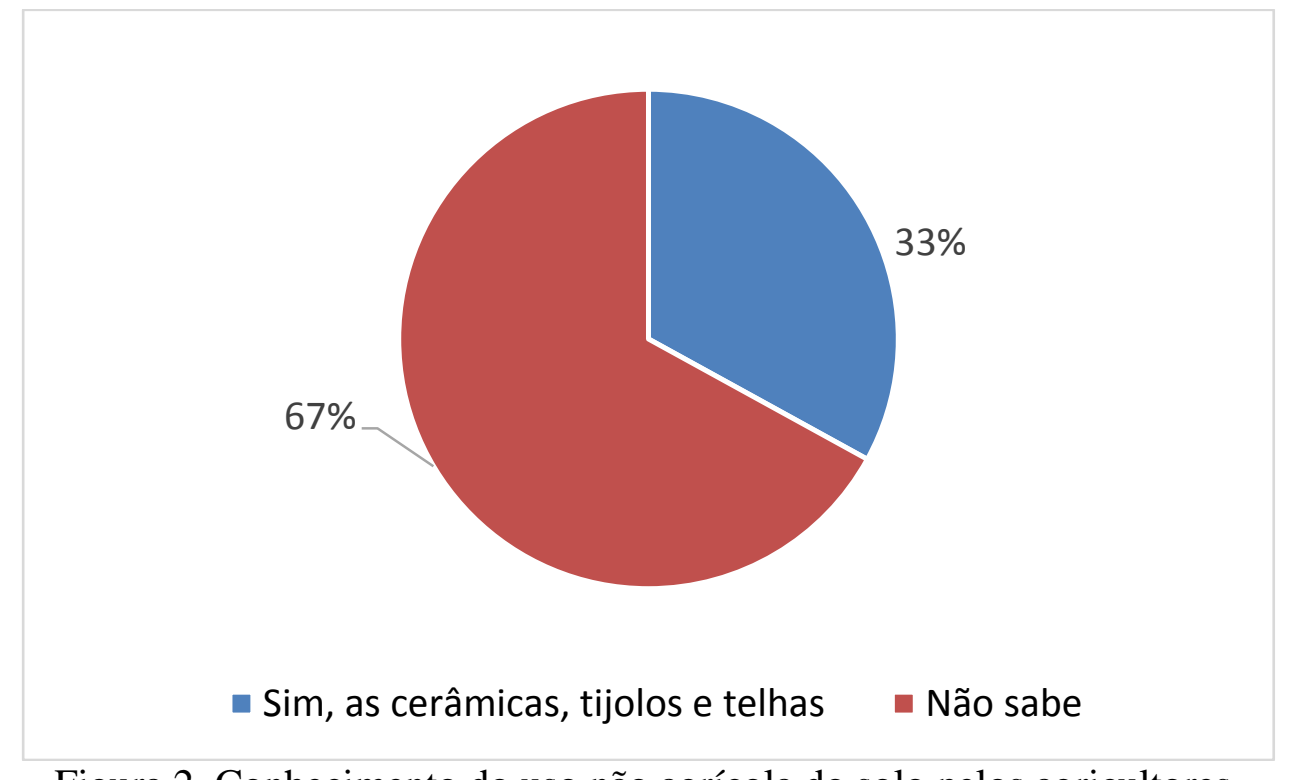

Figura 2. Conhecimento do uso não agrícola do solo pelos agricultores. 
O conhecimento popular do uso do solo tem sido cada vez mais reconhecido e valorizado. Segundo Alves et al. (2005) isso implica que o conhecimento popular, embora sem base científica, possui sua própria racionalidade e complexidade. Além disso, é importante ressaltar que o uso múltiplo do solo é uma característica particular das populações rurais, sobretudo para a confecção de cerâmica artesanal (CORREIA et al., 2004).

Questionados sobre o uso do solo como matéria prima pra confecção de tinta ecológica, apenas 6\% disseram já ter tido informação sobre a atividade.

O solo, verdadeiro mosaico de cores, apresenta em suas potencialidades, a possibilidade do uso na pintura. Esse processo de baixo custo e impacto ambiental mínimo, compreende produtos, técnicas e metodologias que visam a transformação social, favorecendo a organização das comunidades, desenvolvendo a criatividade e ocasionando a melhoria da autoestima dos envolvidos, além de proporcionar alternativa de renda (VITAL et al., 2011).

A pintura a base de tinta de terra surge como possibilidade inovadora para a promoção de uma nova postura frente aos recursos edáficos. Este processo, de baixo custo e impacto ambiental mínimo (o material é atóxico, apresenta boa qualidade e durabilidade, com custo $30 \%$ inferior ao da tinta convencional), compreende produtos, técnicas e metodologias que visam a transformação social, favorecendo a organização das comunidades por meio do exercício da cooperação entre as pessoas, desenvolvendo a criatividade e ocasionando a melhoria da autoestima dos envolvidos (AZEVEDO e OLIVEIRA et al., 2016).

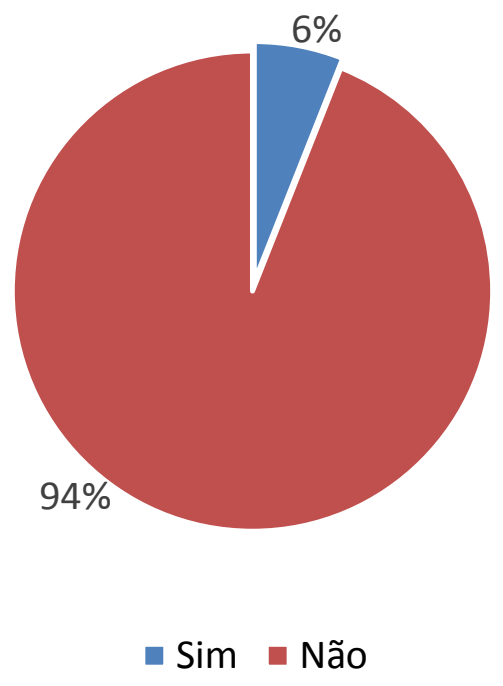

Figura 3. Respostas dos agricultores sobre o conhecimento da geotinta.

Após a realização da oficina de geotinta, quando então foram pintadas as paredes externas da associação, com a participação dos agricultores, estes foram indagados sobre sua visão da atividade e da possibilidade da atividade de pintura com tinta de terra poder agregar renda às suas atividades e ser instrumento de valorização do solo.

No processo de desenvolvimento a técnica, que tem na terra a matéria-prima principal, evoluiu e ganhou espaço na pintura de casas em comunidades rurais e, mais recentemente, nas artes plásticas. As atividades são executadas dentro dos princípios da bioarquitetura, bioconstrução e Agroecologia. Por outro lado a atividade pode contribuir com o embelezamento da paisagem rural, favorecendo a melhoria da aparência das habitações rurais, das instalações comunitárias e dos empreendimentos turísticos, situando-se 
como inovação, desde que as construções humanas exigem qualificação e técnicas cada vez mais apropriadas, vantajosas e sustentáveis, que atendam às demandas do mercado, sempre mais focado no pilar do ecologicamente correto, na inovação tecnológica (ORR, 2002).

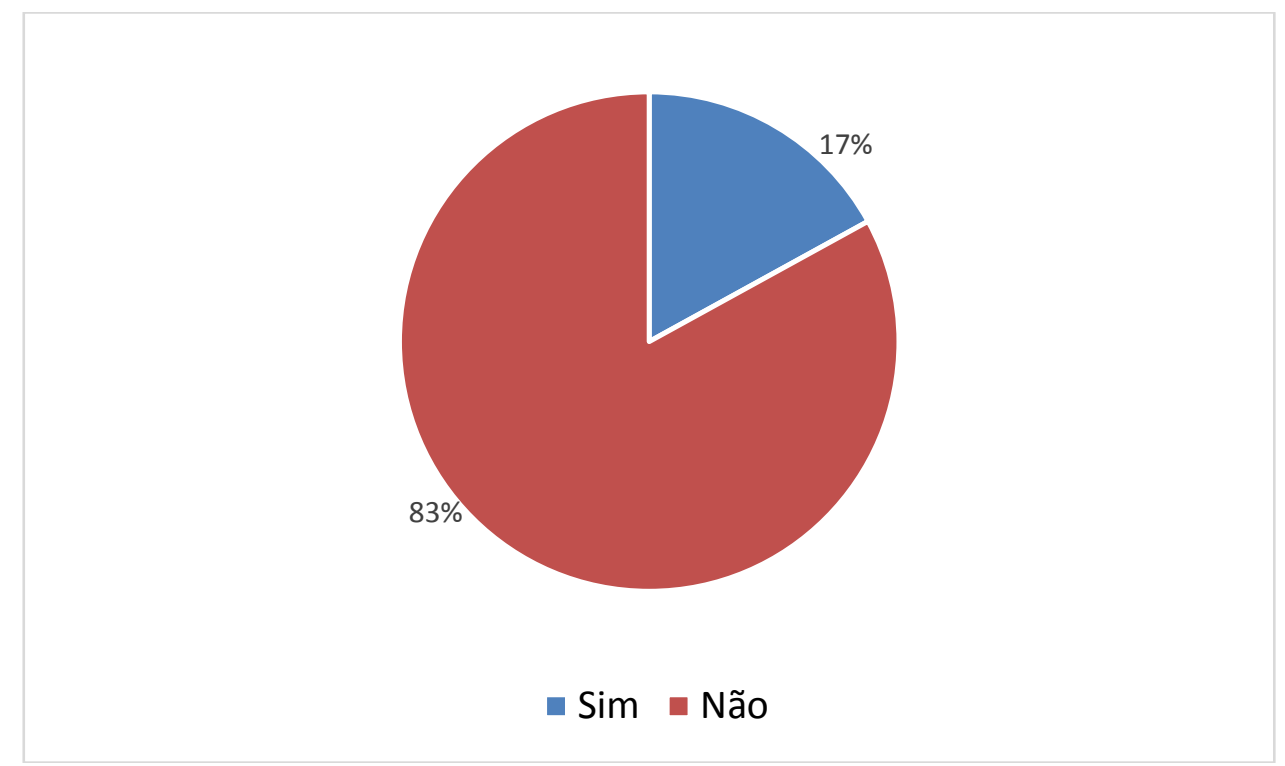

Figura 4. Percepção sobre a possibilidade de a tinta de terra gerar renda.

Quando os agricultores foram questionados a respeito da utilização da tinta de terra como alternativa pra gerar renda, apenas $17 \%$ afirmaram conhecer essa possibilidade, sendo que $83 \%$ afirmaram desconhecer tal potencialidade.

Numa época de globalização e de um avançado estágio tecnológico, associado a um crescimento sem precedentes do desemprego, descobrir

\section{CONCLUSÕES}

O estudo de percepção apontou que os agricultores apresentam conhecimento moderado sobre as características do solo, mas não sobre as potencialidades de uso não agrícola. Ressalta-se a importância desses estudos para um melhor planejamento de políticas de conservação dos recursos naturais pois a percepção da população quanto ao uso e exploração do solo aponta para as alternativas e metodologias de conservação, que poderão ajudar as pessoas a perceberem mais o seu meio, conscientizando-se da necessidade de preservação. alternativas é reabrir possibilidades de profissionalização numa sociedade fortemente estimulada pelo consumo, fortalecendo a cidadania e a força do trabalho. A ocupação, por qualquer que seja ela, valoriza o ser humano no seio da sociedade, melhora a sua autoestima e lhe mostra o caminho do crescimento pessoal, reduzindo as desigualdades sociais (AZEVEDO e OLIVEIRA et al., 2016).

A Oficina de Geotinta promoveu a interação entre agricultores e acadêmicos, sensibilizando para o interesse quanto ao entendimento das características morfológicas do solo, como possibilidade de valorização dos recursos edáficos e geração de trabalho e renda.

A geotinta firma-se assim, como ecotecnologia, promotora de possibilidades de fortalecer o protagonismo do povo do campo, dando visibilidade aos saberes locais, tanto quanto, apresentando-se como alternativa de discutir a valorização dos recursos edáficos em seus usos agrícola e não agrícola. 


\section{AGRADECIMENTOS}

Aos agricultores da Comunidade Rural do Sítio Salão, em Serra Branca (PB), pela

\section{REFERÊNCIAS BIBLIOGRÁFICAS}

ALVES, A.G.C.; MARQUES, J.G.W. Etnopedologia: uma nova disciplina? In: VIDAL-TORRADO, P. Tópicos em ciência do solo. Viçosa: Sociedade Brasileira de Ciência do Solo, 2005. v. 4, cap.8, p.321-344.

AZEVEDO, G. H. de.; OLIVEIRA, D. dos S.; ARAÚJO J. M. M. de.; CAVALCANTE F. L.; VITAL A. de F. M. A potencialidade não agrícola dos solos do semiárido: a tinta de terra como ecotecnologia e inovação. In: I Congresso internacional da diversidade do semiárido, 2016, Campina Grande. Anais do I CONGRESSO INTERNACIONAL DA DIVERSIDADE DO SEMIÁRIDO. , 2016.

CAPECHE, C. L. Educação ambiental tendo o solo como material didático: pintura com tinta de solo e colagem de solo sobre superfícies. (Documentos / Embrapa Solos). Rio de Janeiro: Embrapa Solos, 2010. 60 p.

CARVALHO, A. F.; HONÓRIO, L. de M.; ALMEIDA, M. R. de; SANTOS, P. C. dos.; QUIRINO, P. E. Cores da Terra: fazendo tinta com terra. Universidade Federal de Viçosa. Programa TEIA. Programa Cores da Terra. Viçosa, 2007.

CORREIA, J.R.; LIMA, A.C.S.; ANJOS, L.H.C.; O trabalho do pedólogo e sua relação com comunidades rurais: observações com agricultores familiares no Norte de Minas Gerais. Cad Ci Tecnol. v. 21, p. 447-467, 2004.

LEPSCH, Igo F. Formação e Conservação Dos Solos. Ofina de Textos. São Paulo. 2002. receptividade à equipe da Geotinta do CDSA-UFCG.

LIMA, V.C., LIMA, M. R., MELO, V. F. (Orgs.). O solo no meio ambiente: abordagem para professores do ensino fundamental e médio e alunos do ensino médio. Universidade Federal do Paraná, Departamento de Solos e Engenharia Agrícola, Curitiba, 2009.

ORR, D. W. The nature of design: ecology, culture and human intention. New York: Oxford University Press, 2002.

RESENDE, M.; CURI, N.; REZENDE, S.B. \& CORRÊA, G.F. Pedologia: base para distinção de ambientes. 4.ed. Viçosa, NEPUT, 2002. 367p.

SANGUINETTO, E. Design Ecológico: projetando e construindo tecnologias vivas para o tratamento de efluentes domésticos com reuso das águas. Dissertação (Mestrado). Universidade Federal de Itajubá - UNIFEI. Itajubá, 2010. 228p.

SILVA, A. L. da.; VITAL, A. de F; M.; TEIXEIRA, E. de O.; ARRUDA, O. de A.; RAFAEL, E. M.; ALENCAR, M. L. S. Pintura com terra no sítio: um novo olhar sobre os solos do Cariri Paraibano. Resumos do VIII Congresso Brasileiro de Agroecologia - Porto Alegre/RS. 2013.

RUELLAN, A. Pedologia e desenvolvimento: a ciência do solo a serviço do desenvolvimento. In: MONIZ, A. C.; FURLANI, A. M. C.; FURLANI, P. R.; FREITAS, S. S. (eds.). A responsabilidade social da ciência do solo. Campinas: Sociedade Brasileira de Ciência do Solo, 1988. p. 69-74. 
VILLAR, L. M; ALMEIDA, J. L. V; ALMEIDA, A. J; SOUZA, L. F. B; LIMA, M. C. A; PAULA, V. S. A percepção ambiental entre os habitantes da região noroeste do estado do Rio de Janeiro. Escola Anna Nery Revista de Enfermagem, v .12, n.3, p.537-543, 2008.

VITAL, A. de F. M.; FURTADO, A. H. S. e.; QUINTANS, T. da S.; FREITAS, V. F.; COSTA, T.C. dos S.; FARIAS, E. S. b. de. Educação em Solos na Escola Agrotécnica de Sumé: pintura com terra. Resumos do VII Congresso Brasileiro de Agroecologia - Fortaleza/CE. 2011. 